\title{
La causa de los mártires Agradecimiento a Pedro Casaldáliga
}

\section{Jon Sobrino, Centro de Reflexión Teológica, San Salvador.}

El 16 de febrero Pedro Casaldáliga cumplió 80 años.

La Revista Latinomericana de Teología desea unirse a todos los que le han manifestado gratitud y reconocimiento estos días. Para ello, como don Pedro siempre ha estado muy cercano a El Salvador y sus mártires, muy especialmente a "San Romero de América", reproducimos, algo reelaborado, el artículo de Jon Sobrino "Las grandes causas de don Pedro Casaldáliga: la causa de los mártires". Fue publicado en Pedro Casaldáliga, Las causas que dan sentido a su vida. Retrato de su personalidad, Madrid, Nueva Utopía, 2008.

\section{Encuentros alrededor de mártires}

Conocí a Pedro Casaldáliga en febrero de 1980, en una reunión en Sao Paulo. Yo estaba hablando con Teófilo Cabestrero, cuando don Pedro venía caminando hacia nosotros. Después de darme un abrazo sentí, que le había conocido de toda la vida. Pero ya aquel primer encuentro fue de hecho importante para el tema que me han pedido desarrollar: "Las grandes causas de don Pedro Casaldáliga: la causa de los mártires".

Yo llegaba de El Salvador. El país ardía y a Monseñor Romero le llegaban las llamas de todas partes, y también —y muy dolorosamente para él- de jerarquías, locales y vaticanas. Cuando tuve la oportunidad de escuchar a Casaldáliga, también obispo y también inmerso en graves problemas, me impactó cómo manejaba los que le venían de la Iglesia institución. Y se me quedó grabada una frase suya: "en rebelde fidelidad". Así también vivía Monseñor Romero en la Iglesia, aunque él no era dado a ese lenguaje. En aquellos días finales de su vida, la carga era muy pesada. En Roma, ya en 1978, habían pensado en retirarlo de 
su ministerio arzobispal. Y a comienzos de 1980 hasta de Washington llegaban emisarios al Vaticano para buscar frenarlo y callarlo. El peso del imperio caía sobre Monseñor.

Todo esto me vino a la mente al conocer a Casaldáliga, y se me ocurrió pedirle un favor: que le escribiera a Monseñor Romero, dándole ánimos como hermano obispo en sus problemas con la Iglesia institucional. Estaba seguro de que Monseñor quedaría confortado por Casaldáliga.

El 24 de marzo, Monseñor Romero moría asesinado. Días más tarde don Pedro me escribió una carta, fechada en Sao Felix, el 8 de mayo ${ }^{1}$.

Nos llegó - a vosotros imagino con qué tremenda fuerza y proximidadla trágica "buena nueva" de la muerte de ROMERO. Me pedíais una carta para él. Eso me conmueve. Se la he escrito infinidad de veces estos días. Lo siento como un hermano mayor, como un precursor amado y peligroso. Como un santo de América, pastor y mártir de la total fidelidad... No le faltan homenajes ahora, Incluso los que matan a los profetas saben levantarles monumentos, después de muertos. Ya lo decía el Señor. Veo, sin embargo, que la muerte de Romero ha calado hondo. Ésta ha sido su mejor homilía, indiscutiblemente... Incluyo un poema a Romero.

El poema "San Romero de América" se ha convertido en un canto universal a Monseñor, y es bien conocido. En él han quedado retratados y unidos para siempre Monseñor Romero, el profeta cantado, y don Pedro Casaldáliga, el profeta cantor. Desde entonces, Monseñor Romero ha estado presente, de una u otra forma, en mis encuentros con don Pedro.

A pesar de muchas invitaciones, Casaldáliga nunca había aceptado la invitación a venir a El Salvador. Ello suponía abandonar Brasil, lo que había prometido no hacer, en una especie de juramento de permanecer siempre con su pueblo brasileiro, como nos lo contó más tarde. Pero cuando en Nicaragua el gobierno de Reagan rompió no ya las reglas del bien, sino las reglas del mal, en 1985, Casaldáliga también rompió su promesa después de diecisiete años y fue a Nicaragua a acompañar al pueblo agredido. Entonces, lo invité a venir a San Salvador: "Ven, aunque no sea más que un día, a visitar la tumba de Monseñor". Y vino. Don Pedro conoció a Ellacuría y a los mártires de la UCA, y entablaron una entrañable amistad. En marzo de 1990 regresó a celebrar el X aniversario de Monseñor Romero, y lo primero que hizo fue venir al jardín de rosas, donde habían sido asesinados los jesuitas y las dos mujeres, cuatro meses antes, el 16 de noviembre de 1989. Le pedí unos versos para ellos. Y esos días escribió estas dos décimas:

1. La publiqué como dirigida a todos, y por eso el texto redactado está en plural, en ECA 379 (1980) 491. 


\section{Clamor de aniversario}

Romero, Romero, hermano, Van diez años de tu muerte. ¿Tu muerte habrá sido en vano?

Tu pueblo sigue en la suerte de una vida prohibida y sigue de muerte herida la paz en El Salvador y es un último clamor toda la sangre vertida con tu sangre de pastor.

Capilla del Hospitalito 22 de marzo de 1990

\section{La UCA y el pueblo herido}

Ya sois la verdad en cruz

y la ciencia en profecía

y es total la Compañía,

compañeros de Jesús.

El juramento cumplido

la UCA y el pueblo herido

dictan la misma lección

desde las cátedras fosas

y Obdulio cuida las rosas

de nuestra liberación.

Jardín de rosas

23 de marzo de 1990

He comenzado con estos recuerdos para decir que mi contacto personal con Pedro Casaldáliga ha estado rodeado de "mártires", de Monseñor Romero y de muchos otros. "La causa" que me toca exponer la siento personalmente como muy real. Al hablar ahora sobre don Pedro no hay exultación artificiosa, sino sencilla honradez.

Desde esa experiencia de martirio real, voy a hacer algunas reflexiones sobre Casaldáliga y el martirio. Si las entremezclo con recuerdos y palabras de Monseñor Romero e Ignacio Ellacuría, es para que la teología de textos, es decir, conceptos sobre el martirio, quede fecundada por la teología de testigos, es decir, mártires reales, con quienes ha vivido y a quienes ha cantado don Pedro.

\section{Causa y biografía}

Los mártires no son una causa más. En ellos - y en mantenerlos vivosconvergen una constelación de realidades, que son las más fundamentales para el ser humano y para el creyente: Dios e historia, gracia y pecado, vida y muerte, todo lo cual se echa de ver en cualquier texto de Casaldáliga sobre mártires. Pero hay que insistir desde el principio en algo específico del tratamiento que Casaldáliga hace del martirio. A veces, el martirio es sólo una realidad que se conoce "de oídas" o "de leídas", pero otras veces, en alguna de sus formas, es una realidad "vivida de cerca“, y entonces, el análisis cobra una profundidad especial.

Cuando esto ocurre, el martirio deja de ser sólo un tema de interés para la devoción genérica de los fieles, o de historiadores y pensadores, o de miembros de los dicasterios que investigan si hubo o no martirio. Se impone, ante todo, como algo real, en lo que convergen las realidades más fundamentales de los seres humanos: amor, entrega y fidelidad, por una parte, crueldad, cinismo, mentira, por otra. En cercanía a la realidad de martirios reales se puede aprehender, "hacerse cargo", de qué es el martirio, más allá de conceptos teológicos y canó- 
nicos, útiles por otros capítulos. Y se impone quiénes son — se los llame como se los llame - realmente mártires.

Desde la honradez con la realidad martirial, vivida de cerca, surgen una tras otra, inevitablemente, las preguntas más importantes. Ante todo, por qué les arrebataron la vida, qué causa defendían, quién es responsable, y también qué responsabilidad tenemos nosotros. Surge también la pregunta de qué exigen de nosotros, es decir, qué vamos a hacer con los mártires y con qué debemos cargar para proseguir su causa. Y por último, surge la pregunta de si esa vida entregada hace avanzar realmente la causa de Dios y de la humanidad, si los mártires cargan con nosotros y nos dan vida, o si todo termina en el absurdo.

El martirio es, pues, captado en un concepto de realidad, con lo que ésta tiene de oneroso y con la que hay que cargar, y con lo que tiene - escandalosamente- de bienaventurado y puede cargar con nosotros. Es captado en un concepto práxico, que incluye la disposición a un hacer, a proseguir una causa. Y es captado en un concepto de sentido, que puede configurar y otorgar unidad y coherencia última a las múltiples dimensiones de la vida.

En ésas ha vivido Casaldáliga. En él "causa" y "biografía" han estado muy unidas, hasta el punto que, como lo escuché hace tiempo en boca de amigos suyos, "Casaldáliga está deseando ser mártir". Y creo entender lo que quieren decir. Don Pedro no es masoquista, canta a la vida con total esperanza. Menos aún es arrogante, como aquellos cristianos de los primeros siglos, que buscaban activamente el martirio para lograr una mayor santidad, hasta el punto que la jerarquía tuvo que frenarlos y aun condenarlos. Pero algo importante se expresa en ese deseo. No consiste en engrosar la lista de mártires, sino en proclamar con radicalidad su amor a las víctimas, y en decir que con ellas quieren solidarizarse hasta el final. Es la desmesura del amor. Es lo que don Pedro ve en Jesús, el hermano mayor, primogénito de la resurrección, pero antes primogénito de la fe y primogénito en la entrega y el amor.

A lo largo de su vida, Casaldáliga ha recibido muchas amenazas y ataques. Por lo que conozco, el más directo ocurrió el 12 de octubre de 1976. Con el padre Burnier, jesuita brasileño, fue a la estación de policía de Ribeiro do Garças para protestar por la detención de varias personas. Así lo cuenta: "Dos mujeres, sobre todo, doña Margarita y dona Santana, estaban sufriendo en la comisaría, impotentes, y bajo torturas, esa represión inhumana: un día sin comer ni beber, de rodillas, brazos en cruz, agujas en la garganta y debajo de las uñas... Eran más de las siete y sus gritos se oían desde la calle: "No me golpee'". Don Pedro entró a la comisaría con el padre Burnier. Éste dijo a los soldados que iba a denunciar lo que estaba sucediendo. "Entonces fue golpeado varias veces, y un policía le disparó a la cabeza". A pesar de los esfuerzos de Casaldáliga murió a las pocas horas. 
Defender a dos mujeres víctimas - y denunciar los atropellos de los potentados - era la causa inmediata. Pero con ello, él y el jesuita asesinado querían defender una causa mayor. Así lo dijo el Padre Arrupe, en aquel tiempo superior general del Padre Burnier. "Líderes como el Obispo Casaldáliga y el padre Burnier han trabajado valerosamente para ayudar a los indios empobrecidos a los que, en repetidos intentos, se ha pretendido arrojar de la tierra en que han vivido y trabajado durante muchos años" ${ }^{2}$. Esa era la causa mayor: la justicia, la defensa del derecho de los indios a sus tierras y a la vida.

Esto sucedió hace más de treinta años, pero ha marcado a don Pedro, su poesía, su teología y su fe. En absoluto da la impresión de haber quedado traumado, preocupado de su seguridad. Sí comunica haber captado la realidad más verdadera que se expresa en el "martirio": amor y defensa de las víctimas y fidelidad hasta el final en presencia de injusticia, violencia, asesinato... El martirio no meramente pensado, sino aprehendido en cercanía a su realidad, remite - mejor que cualquier dogma, teología o canon - a la cruz de Jesús. Y también a su resurrección. Es la experiencia de don Pedro. Tras sus palabras, muchas veces poéticas, hay una captación de realidad que le permite hablar así.

El caso de Monseñor Romero es paradigmático. Vivió cercano a muchos martirios, y, al final, al suyo propio. Y esa cercanía a la realidad del martirio, pienso que le posibilitó hablar de manera novedosa y muchas veces sublime de las cosas más importantes para los seres humanos. Esto es lo que dijo poco antes de su asesinato:

He sido frecuentemente amenazado de muerte. Debo decirles que, como cristiano, no creo en la muerte sin resurrección. Si me matan resucitaré en el pueblo salvadoreño. Se lo digo sin ninguna jactancia, con la más grande humildad. Como pastor estoy obligado por mandato divino a dar la vida por quienes amo, que son todos los salvadoreños, aun por aquellos que vayan a asesinarme. Si llegaran a cumplirse las amenazas, desde ya ofrezco a Dios mi sangre por la redención y resurrección de El Salvador. El martirio es una gracia que no creo merecer. Pero si Dios acepta el sacrificio de mi vida, que mi sangre sea semilla de libertad y la señal que la esperanza será pronto una realidad. Mi muerte, si es aceptada por Dios, sea por la liberación de mi pueblo y como un testimonio de esperanza en el futuro. Puede usted decir, si llegasen a matarme, que perdono y bendigo a quienes lo hagan. Ojalá, sí se convenzan que perderán su tiempo. Un obispo morirá, pero la Iglesia de Dios, que es el pueblo, no perecerá jamás.

Muerte, resurrección, humildad, mandato divino, dar la vida, gracia, redención y liberación, libertad y esperanza de El Salvador, perdón y bendición a los

2. Noticias de Roma, 27 de octubre de 1976. 
asesinos, "el pueblo no perecerá jamás"... Todas estas realidades giran alrededor de la vida de Monseñor, pero las capta, las aprehende, "se hace cargo de ellas", con mayor clarividencia cuando siente cercano el martirio. Y se trata de su martirio. Ahí está la raíz de la elocuencia inigualable de esas palabras - como lo fueron las de Policarpo o Ignacio de Antioquía.

El martirio real, cercano a la propia vida, hace posible una epistemología específica, y en buena medida insustituible, para captar la realidad y para que ésta no permanezca como objeto de mera contemplación, sino que se convierta en causa propia, por la que trabajar y luchar. En lenguaje de Ellacuría - primero pensador y después mártir-, estar en la verdad de las cosas, en medio de su realidad real, no sólo pensada, las ilumina de una manera especial. E invita a encargarnos de ellas, cargando con lo que pesan en sí mismas, con sus presupuestos y sus consecuencias - a lo que siempre añadimos, dejando que ellas carguen con nosotros. Es la experiencia de muchos en cercanía a la realidad de mártires reales.

A continuación vamos a hacer algunas reflexiones sobre cómo, desde esa cercanía, Pedro Casaldáliga ha captado la realidad de los mártires, y lo que eso posibilita y exige de nosotros. Y lo planteamos en forma de pregunta: qué hacer con los mártires.

\section{Qué hacer con los mártires}

Hace algunos años la pregunta hubiese sorprendido, pero hoy es necesaria, pues en el continente latinoamericano ha habido muchos miles de mártires —así lo reconoce Aparecida, usando el término "mártires" con toda naturalidad. Ha habido un vendaval de crueldad, pero también ha habido un vendaval de generosidad. Sin embargo, no muchos saben qué hacer con los mártires. No lo favorece el pensamiento Light, que se ha introducido en las iglesias, y ciertamente lo reprimen los poderes oscuros, aquellos que hicieron uso de la persecución y del asesinato para frenar a Medellín. Quieren que los ignoremos - y que nadie pregunte por sus asesinos. En la Iglesia institución algunos jerarcas los recuerdan y los ponen a producir. Otros los silencian, o les hacen morir la muerte de mil distinciones y casuísticas. Pocos son los que, con alborozo y sin miedo, los ponen en el centro de una Iglesia que debe ser pueblo de Dios e Iglesia de los pobres. Y en el centro deben estar, porque su pascua es la actualización más real de la pascua de Jesús.

El hecho fundamental en cualquier caso sigue en pie. En el tercer mundo, mucha gente llama mártires a una multitud de testigos, en muchos países, encabezados por Monseñor Romero, "pastor y mártir nuestro", dice don Pedro. No murieron echados a los leones en el circo romano, sino asesinados por los escuadrones de la muerte y de la seguridad nacional. Y la pregunta fundamental es qué hacer con ellos. 
Ese hacer es de todo el pueblo de Dios. También la jerarquía tiene cosas importantes que hacer, sin duda. Y ojalá las haga bien. Pero no hay que olvidar que los mártires no son propiedad de una institución, sino que son, ante todo, mártires del pueblo de Dios y de la humanidad.

Como en los primeros siglos, también hoy hay que mostrarles veneración y agradecimiento. Y, en América Latina ciertamente, hay que mantener su causa actualizadamente: anunciar e iniciar el reino de Dios, "la causa más noble de la humanidad", que decía Rutilio Grande, el primer sacerdote asesinado en El Salvador. Cómo ve don Pedro esa causa se analiza en detalle en otros capítulos de este libro: la causa de la patria grande, de los pobres, de la tierra, la causa indígena, negra, de la mujer, de la Iglesia... Lo que queremos analizar ahora es, ayudados por Pedro Casaldáliga, cómo ubicarlos bien en nuestra realidad y como ubicarnos nosotros bien ante ellos.

\subsection{Mirada limpia ante toda entrega de la vida}

Comenzamos con una reflexión que puede sorprender, pero que nos parece necesaria: hay que comenzar aceptando, en silencio, sin argumentos, la desmesura del amor, que se expresa en el martirio. La "causa" le otorga una cierta racionalidad, pero en el "dar la vida" hay una misteriosa ultimidad, tremens et fascinans. Lo decimos porque no hay que darlo por supuesto. Los seres humanos podemos estropearlo todo, incluso el modo de mirar a los mártires.

Recordemos, a modo de ejemplo, que en 1995, en la Congregación General XXXIV de los jesuitas, algunos de los asistentes estaban sorprendidos de que los latinoamericanos hablasen con naturalidad de "mártires por la justicia" — y aun sin mala voluntad, algunos podían pensar que exageraban, y podía incluso asomar la duda de sí no habría habido un exceso de política, que es lo que les habría llevado a la muerte. Por otro lado, otros quedaron impactados al escuchar historias de persecución y martirio, en los países comunistas del este de Europa, como si la idea hubiera ya desaparecido del imaginario religioso de América Latina. Por lo que conozco, no hubo problemas, sino gran respeto, mutua comprensión y aun admiración de todos ante lo que parecían novedades. Pero sí apareció que no es absolutamente evidente aceptar que hay mártires y qué es un mártir. En definitiva, qué es ese misterio último de entregar la vida.

Otras veces, el problema es real, y a veces puede ser grave. Pienso que es lo que ha ocurrido con la beatificación de los 498 mártires en España. La generosidad de la entrega es reconocida. Pero también es claro que se han introducido visiones miopes de lo ocurrido e incluso intereses políticos, manipuladores — sin que haya quedado clara la dignidad de muchas otras muertes de personas de fe $\mathrm{o}$, al menos, de buena voluntad que estaban en otro lugar o en otro bando. 
Aquí, en El Salvador, los mártires son, por un lado, amados y venerados, por otro, son odiados y ocultados, y existe una tercera forma de considerarlos que no es lo nítida que debiera. Ocurre tristemente alrededor de Monseñor Romero. Se dice que su beatificación tiene que esperar - lo cual no es problema para la fe real de la gente, y don Pedro, si no recuerdo mal, advierte que sería blasfemia querer canonizarlo, como si no fuera ya santo. Pero ocurren tales cosas a lo largo del proceso que intereses, que nada tienen que ver con Monseñor ni con los víctimas, hacen que se desvíe la atención del hecho fundamental: la entrega total de un ser humano, libre y generosa, por amor, a un pueblo de pobres. El problema consiste en hacer pasar el hecho fundamental, eficazmente, a un segundo o tercer lugar, de modo que puedan aparecer en primer lugar normativas, conveniencias, intereses

Las razones que, en público, dan las curias para que el proceso no avance con fluidez no tienen que ver con la ortodoxia y la ortopraxis, pues Monseñor ha pasado la prueba de ambas. Al parecer, tampoco es ya problema si el martirio fue in odium fidei o in odium iustitiae, o, como se discutió en un momento, si era mejor elegir el camino de "confesor" o el de "mártir". La razón del estancamiento, se ha dicho, es el peligro de que la figura de Monseñor sea manipulada políticamente, sobre todo por la izquierda.

Por coincidencia, escribimos estas líneas en el XXVIII aniversario de su asesinato, y por ello, queremos ante todo desenmascarar la simetría con se habla de manipulación. Sea cual fuere la manipulación por parte de la izquierda, entonces y ahora, poco se recuerda, y menos en detalle, la macabra manipulación de la derecha, la cual no sólo lo manipuló, sino que lo difamó. Lo acusó de comunista. Escribió cosas aberrantes - "Monseñor Romero vende su alma al diablo", fue el titular de un periódico ultraderechista de la época. Y lo asesinó.

Sí la denunció, en palabras que todavía producen escalofríos, Monseñor Rivera, y es importante recordarlo estos días. Poco antes de las elecciones de 1995, dijo en la homilía dominical del 6 de marzo: "Cómo se puede votar pensando en el futuro si se pasa por alto quiénes son los asesinos de Monseñor Romero y quién organizó el complot contra su vida y dio la orden de matarlo... Lo quieran o no la sombra de este crimen sacrílego persigue a quienes, aun después de catorce años, siguen impenitentes idolatrando al hombre que quiso resolver los problemas de El Salvador a sangre y fuego". En El Salvador, todo el mundo entendió que se estaba refiriendo al ex mayor Roberto D'Aubuisson, fundador del partido ARENA. Esta manipulación de la persona y la obra de Monseñor Romero, por parte de la derecha, persiste en el odio hacia Monseñor, en el desprecio hacia el documento de Naciones Unidas, de 1993, que establece la responsabilidad del ex mayor en su asesinato.

Recordamos estas cosas (diversidad comprensible de visiones sobre los mártires, manipulaciones, reales o supuestas) para insistir en la tesis fundamental: 
cuán difícil es tener la mirada limpia para ver a los mártires y tener honradez para que otras consideraciones, aun legítimas por otros capítulos, no enturbien esa mirada. Y sobre todo, cuán difícil es interiorizar el inmenso misterio de que hay seres humanos que dan la vida libremente y aceptar que ese misterio se ha hecho realidad en muchísimas muertes.

Mantener ese misterio del "dar la vida" es fundamental para empezar a hablar de mártires. Y es lo que don Pedro transmite al hablar de ellos. Para mostrarlo con la máxima claridad voy a citar un texto suyo de febrero de 1992, desconocido entre nosotros, sobre el asesinato de sus hermanos claretianos, en Barbastro, durante la guerra civil española. El contexto mediático es hoy controvertido, como es sabido. La finura de espíritu de don Pedro consiste en saber ir a la verdad última de las cosas en medio de la controversia, sin ceder a intereses, por supuesto, y sin quedarse en verdades penúltimas. Por eso lo citamos.

Llegada la hora del Huerto y el camino del calvario y la Cruz —en el salón de los escolapios, por la calles acosadas o en el valle de San Miguel- toda la vocación cristiana y claretiana de nuestros hermanos estalló en un testimonio pocas veces igualado en las actas de los mártires antiguos o modernos: aquel estado de oración, la Eucaristía de catacumbas, sus escritos estremecedores, sus cantos, sus besos, su exultación... Era el clímax del seguimiento de Jesús; la pasión por su causa, el Reino —el Reino de Cristo Rey y su "reinado social" explícitamente—; era el mismo perdón de Jesús a sus verdugos; la alegría de haber sido hallados "dignos de padecer por el Nombre"; y hasta la renuncia al sacerdocio o al apostolado, en favor del martirio tempranero ${ }^{3}$.

Sobre los mártires en la España de aquellos años se deben decir muchas cosas sin caer en los facilismos que hemos leído en la prensa. Pero don Pedro sí sabe hablar bien de ellos, sin que las ambigüedades de la cruzada lo priven de luz para ver lo fundamental y reaccionar con honradez y agradecimiento. Don Pedro sabe que hay que contextualizar el martirio, pero que no hay que trivializar la entrega de la vida, de cualquier vida. No es pequeño aporte.

Ciertamente, los mártires en América Latina, y en el tercer mundo, son cosa distinta a los mártires de la guerra civil española recientemente beatificados, lo cual es fácil de captar. Pero ver la diferencia, no garantiza automáticamente la mirada limpia ante los mártires. Puede llegar a ser un caso límite de honradez con lo real. Don Pedro ayuda a captar la hondura del martirio.

\subsection{Ubicarlos bien junto a las pobres y las víctimas}

A los mártires latinoamericanos los mataron por defender a pobres inocentes e indefensos, que morían la muerte lenta de la opresión y la muerte violenta de

3. Texto de 1992. 
la represión. Ha habido mártires porque antes ha habido víctimas. Y si ha habido muchos y muy generosos mártires es porque muchas eran las víctimas, a las cuales había que defender, y grande la crueldad de la cual había que liberarlas $-\mathrm{y}$ también porque ocurrió el milagro de una nueva conciencia cristiana, promovido por Medellín, la cristología del Jesús histórico, la teología de la liberación...

Esto es lo primero que hay que recordar para ubicarlos bien. Pero tampoco es fácil, y menos a medida que pasa el tiempo. Se ignoran u olvidan las víctimas, y así se introyectan dudas sobre lo esencial de la entrega martirial. Pero bien ubicados, es fácil comprender a los mártires: fueron gente que quisieron salvar y liberar. Se hicieron eco de las palabras de Dios: "He visto sus sufrimientos y he escuchado los clamores que les arrancan sus capataces en Egipto. He bajado a liberarlos". Prosiguieron el camino de Jesús: compasión, denuncia y fortaleza. Fueron gente de amor.

De aquí se derivan consecuencias importantes. La primera y fundamental es que antes de pensar en los mártires hay que traer a la memoria a las víctimas, que los movieron a ser lo que llegaron a ser. Como hacía Monseñor Romero en sus homilías, hay que nombrar, una a una, a todas las víctimas, sin olvidar a ninguna de ellas.

Casaldáliga siempre las tiene presentes, y periódicamente las recuerda en su totalidad, como la verdad de todo un mundo victimizado. Muy recientemente lo ha vuelto a decir: "África ha sido llamada 'el calabozo del mundo', una shoá continental. 2,500 millones de personas sobreviven en la tierra con menos de 2 euros al día y 25,000 personas mueren diariamente de hambre, según la FAO. La desertificación amenaza la vida de 1,200 millones de personas en un centenar de países" ‘. ¿Cuántos hombres y mujeres han sufrido persecución y martirio por solidarizarse con estas víctimas y defenderlas?

La segundo que hay que tener en cuenta es que también esas víctimas deben — o ciertamente pueden - ser consideradas como mártires, aunque el lenguaje se torne análogo. Pensamos que en ellas acaece el martirio primordial. A ello apuntan sub specie contrarii unas palabras recientes de don Pedro ante la problemática de la amenaza de lo relativo y el olvido de lo absoluto: "todo es relativo menos Dios y el hambre"5. "El hambre", pobres y víctimas, es lo absoluto. Sólo ellos, con Dios a su lado. Y desde hace muchos años se ha fijado en víctimas muy cercanas para él, especialmente los indígenas con quienes vive. En 1983, escribió un artículo emblemático: "los indios 'crucificados' un caso anónimo de martirio colectivo". Como Monseñor Romero y el padre Ellacuría, les estaba diciendo: "Ustedes son el siervo sufriente de Yahvé. Ustedes son Cristo crucifi-

4. "Utopía necesaria como el pan de cada día", enero de 2006.

5. Carta circular, enero de 2007.

6. Concilium 183 (1983) pp. 382-389. 
cado". Palabras que les otorgan inigualable dignidad, pero que antes expresan lo fundamental: son víctimas.

Poner nombre a las víctimas, y sobre todo a los pueblos crucificados, sigue siendo una necesidad hasta el día de hoy - Mons. Romero, Martin Luther King, Gandhi, mal que bien son recordados. Pero no ocurre con los pueblos crucificados, para vergüenza de nuestra humanidad. Los cuatro millones de muertos en el Congo, en una guerra, en definitiva, para que las grandes empresas del norte pudieran apoderarse del coltán, son unos desconocidos, como los africanos hundidos en el fondo del atlántico. Y entre nosotros, los muertos y desaparecidos en El Salvador y Guatemala, siguen, muchos de ellos, sin nombre, sin dignidad, sin reparación. Los de la derecha irredenta, además, los seguirán denigrando: "terroristas" - aunque ya no les llaman como antes, en el colmo de la insensatez, "medellinistas".

Don Pedro pone nombre a las víctimas y les da dignidad a todas ellas. Pero se ha fijado de manera especial en los pueblos indígenas de nuestra América. Y hablando sobre ellos, ahonda en dimensiones muy importantes de nuestra vida cristiana. Veámoslo.

Para empezar estos pueblos crucificados expresan la dimensión dialéctica de la misión cristiana, en lo que insiste don Pedro: "la Iglesia solamente será anuncio del reino en la medida en que sea denuncia del antirreino" ". No es fácil mantener esa convicción, pero mucho más difícil es reconocer nuestra participación en el antirreino, lo cual es absolutamente necesario. Los pueblos indígenas mártires nos acusan de pecado, nos deben llevar al remordimiento y nos exigen conversión eficaz, verdadero "vuelco" en nuestro modo de proceder. "Para nosotros los cristianos, para las iglesias en cuanto iglesias, la tragedia indígena es una acusación histórica no valorada nunca suficientemente. Debería ser un remordimiento asumido, una convulsión profética y eficaz"8.

Nos declaran nuestra más honda verdad: "hemos sido más perseguidores que perseguidos". A ello apuntaba Ellacuría: mirando al tercer mundo, el primer mundo, como en un espejo invertido, se conocerá en su verdad. Por lo que producimos, sabremos lo que somos. Los perseguidos desenmascaran nuestra realidad de perseguidores. Y esto hay que decirlo también de las iglesias, sin que haya que sorprenderse de ello. Afirman los historiadores que "una Iglesia que fue marginada y perseguida, muy pronto, cuando se convirtió en garante de la ideología dominante, marginó y persiguió" ${ }^{10}$.

7. Em defes, p. 12

8. Ibíd., p. 387.

9. Ibíd.

10. R. Aguirre, "La persecución en el cristianismo primitivo", Revista Latinoamericana de Teología 37 (1986) 39. 
Según esto, ¿qué hacer con los mártires? Proseguir su causa, ciertamente, pero con conciencia de reparación. "La Iglesia solamente podrá ser testimonio de perdón y de gracia en la medida en que ella misma sea penitente y gratuita... El anuncio de la Buena Noticia no puede hacerse sin denunciar el genocidio y el etnocidio. Pero al anuncio y denuncia deben preceder la renuncia y la conversión de toda la Iglesia misionera" ${ }^{11}$.

Y un último aporte, llamémoslo así, de los pueblos crucificados: plantean el problema de Dios, la posibilidad o dificultad de la fe, lo que la Iglesia institución no suele tener muy en cuenta. Aunque no podemos entrar en ello sino de puntillas, yo creo que, para don Pedro, la fe en Dios es un don que le ha acompañado siempre, aunque, como dijo en un viaje por Centroamérica en $1995^{12}$, "debo confesar que he ido cambiando de Dios". A ello le fueron moviendo, según él mismo confiesa, por una parte, la teología de la liberación, y por otra, las dictaduras y los verdugos, así como las incomprensiones eclesiásticas. Ingenua, pues, no es su fe. Su Dios siempre ha sido el de Jesús, pero, como él dice, "siempre Único, siempre Mayor, siempre Otro".

Pero dice también que, cuando en su viaje por Centroamérica veía que "algunos sueños se venían abajo", la gente le preguntaba: "Monseñor, ¿dónde está el Dios de los pobres? Yo naturalmente -o sobrenaturalmente- contestaba: 'con los pobres'". Pero seguía asomando la pregunta de la teodicea, y don Pedro habrá tenido que luchar con Dios como Jacob. Lo suyo no es, habitualmente, el lamento. Sin embargo, ante "los indios crucificados" - casi como por excepción, diríamos - deja que éste fluya y que asome el absurdo. "Hace tiempo - desde que entré en contacto habitual con las poblaciones indígenas- que siento la desaparición de pueblos enteros como un absurdo misterio de iniquidad histórica que convierte mi fe en abatimiento. 'Señor, ¿por qué los has abandonado?'. ¿Cómo puede el padre de la vida, el Espíritu creador de toda cultura, permitir tantos aniquilamientos?"13.

Casaldáliga, a diferencia de Iván Karamazov, no hace de este escándalo el punto culminante de su experiencia humana. Igualmente, habla de esperanza y de resurrección. No devuelve, pues, la entrada a un paraíso, donde se arreglen los absurdos, como hace Iván. Pero la comparación no es inútil. También al creyente Casaldáliga "los indios crucificados" le producen el horror que produce a Iván Karamazov "aquel niño descuartizado por perros por orden de un viejo general". En cualquier caso, ese horror es lo que le hace ponerse ante Dios como ninguna otra cosa consigue hacerlo: preguntándose por el abandono de Dios en la cruz y en las cruces.

11. Em defesa, p. 12.

12. Véase "Queda el Dios liberador", Carta a las Iglesias 343 (1995) 6-7.

13. "Los indios crucificados", p. 387. 
Pero además, escandalosamente, las víctimas pueden ser salvación, "fuente de renovación"14. "De la Galilea de los gentiles llegará una luz libertadora"15, palabras con que Pedro Casaldáliga termina su artículo.

La conclusión es que si los mártires están bien ubicados, junto a las víctimas, se tornan elocuentes. Nos remiten al misterio del mal y apuntan al misterio del bien, el que asoma en el siervo doliente. En definitiva, nos remiten al misterio de Dios.

\subsection{Ubicarlos bien junto a Jesús de Nazaret}

Hay mártires por defender a víctimas. Eso quiere decir que la entrega de los mártires es amor y compasión, pero con un matiz fundamental: son defensa y liberación. Las víctimas son producto histórico de "enemigos", de quienes hay que defenderlas, y de "opresores", de quienes hay que liberarlas. El martirio ocurre no por hacer el bien, sino por introducirse en el conflicto social (económico, militar, político, cultural, religioso...) para hacerlo. Así fue con Jesús. Y así es Dios: "toma su defensa y ama a los pobres" (Puebla 1142), y por ese orden. Por esa razón, hemos definido a los mártires latinoamericanos y de todo el tercer mundo como mártires jesuánicos: los que en vida y en muerte, según un más y un menos, se parecen a Jesús ${ }^{16}$.

Para don Pedro eso es claro, pero vamos a detenernos en ello, pues no hay que darlo por supuesto. Ni siquiera en el documento de Aparecida. Por una parte, a diferencia de otros documentos eclesiásticos recientes, menciona a los mártires y les de gran importancia. Pero, por otra parte, no acaba de presentarlos en la línea del mártir Jesús. Veámoslo.

Aparecida hizo un gran esfuerzo para poner nombre a los pobres del continente, en sus variadas manifestaciones, y también a los mártires. Los comprende en relación con los pobres, con la promoción de la justicia y los derechos humanos (n. 98,140,275). Sin embargo, no acaba de explicar con claridad qué son esos mártires. La razón está en que no analiza a fondo la vida de Jesús, quien vivió en una sociedad de opresores y oprimidos, y quien, por tomar la defensa de los pobres, entró en conflicto con los poderosos y fue asesinado por ellos.

Lo que aquí interesa recalcar es que, sin tener en cuenta ese conflicto, tampoco se entiende la razón histórica del martirio de nuestros días en América Latina, e, ignorado éste, tampoco se historiza adecuadamente la profundidad teologal del amor y del odio (el odium fidei, iustitiae), de la gracia y del pecado, que expresa el martirio.

14. Ibíd., p. 389.

15. Ibíd., p. 388.

16. Véase Jesucristo liberador. Lectura histórico-teológica de Jesús de Nazaret, Madrid, Trotta, 1991, San Salvador, UCA Editores, 1991. 
Don Pedro y Monseñor Romero lo vieron con toda claridad, y lo pudieron ver porque, en definitiva, se hicieron la pregunta clave: “¿por qué se mata?". Decía Monseñor: "Yo creo - y para mí es un orgullo - poder decir que la Arquidiócesis de San Salvador no quiere ser indiferente ni cómplice de la situación de pecado y de violencia estructural que existe en nuestro país ${ }^{17} \ldots$ Se mata porque estorban... [Los mártires] son verdaderos hombres que han ido a los límites peligrosos, donde la UGB [Unión Guerrera Blanca] amenaza, donde se puede señalar a alguien y se termina matándolos, como mataron a Cristo"18.

Este recordatorio fundamental está ausente en el texto de Aparecida ${ }^{19}$. Las consecuencias son empobrecedoras para la comprensión de qué son los mártires, y para saber "qué hacer con ellos", es decir, para saber "cómo ser Iglesia" hoy. Y la raíz es honda: en la cristología de Aparecida aparece, sí, el Jesús que vive con amor y muere por amor, pero no se plantea ni se responde a la pregunta, sencilla y radical, que Ellacuría planteó como central: "por qué muere Jesús y por qué le matan"20.

En Aparecida hay cosas bien dichas sobre Jesús (129-135), pero no se menciona el contexto histórico de su vida y su actuación, lo cual puede ofrecer una imagen de Jesús que, en definitiva, aunque no sea ésa la intención, no acaba de superar una modalidad de cierto docetismo, como si el conflicto social no le alcanzase a él. Por lo que toca al martirio, hay dos serias ausencias.

No se dice que el mensaje de Jesús fue una buena noticia para unos y una mala noticia para otros. La buena nueva se dirige a los pobres y la mala nueva a los ricos (Lc 6, 20-26). Lo mismo dice el evangelio de María: "Derribó a los poderosos de sus tronos y exaltó a los humildes. Llenó de bienes a los hambrientos y despidió a los ricos con las manos vacías" (Lc 1, 52-53). En Jesús había compasión hacia los oprimidos e indignación contra los opresores ${ }^{21}$.

Y tampoco aparece el conflicto de Jesús con los jefes de la nación, a los que denuncia como usurpadores y opresores, y con todos los grupos de poder, del

17. Homilía, 24 de junio de 1979.

18. Homilía, 23 de septiembre de 1979.

19. Véase el clarividente artículo de J. Comblin, "El proyecto de Aparecida", Revista Latinoamericana de Teología 72 (2007) 280.

20. "Por que muere Jesús y por qué le matan", Diakonía 8 (1978) 65-75. Se trata de analizar el significado de su muerte, por una parte, y las razones históricas, por otra. Aunque pueda parecer que la distinción e importancia de ambas cosas está ya está in possessione en la teología, no creo que sea así. Al menos no se le da la debida importancia. Las consecuencias se pueden ver en el texto de Aparecida, lúcido y con aliento en otros temas, pero no en la cristología.

21. Esto no quiere decir que Jesús no buscase salvación para los ricos, ni que hoy no debamos trabajar por ello, en lo que insisten Pedro Trigo y J. A. Pagola, en su conocido libro Jesús. Aproximación histórica, Madrid, 2007. Pero no se puede negar la diferencia de actitud hacia unos y otros, sin lo cual es muy difícil comprender la cruz. 
tipo que fuere: sacerdotes, doctores de la ley, fariseos; conflicto que aparece desde el principio (Mc 3, 6; cfr. Lc 4, 28): los poderosos quieren matarlo. La persecución es, entonces, como "el clima de la vida de Jesús". Su misión es presentada como camino hacia la muerte. Aparecida habla del "amor servicial de Jesús hasta el don de su vida", pero no acaba de decir "por qué matan a Jesús": su denuncia de la corrupción de los jefes del pueblo, del yugo insoportable que imponían al pueblo sencillo, del uso que los jefes hacían de la ley.

Esta cristología rebajada se refleja en lo que dice sobre los mártires. Cita el tema, dice cosas buenas y verdaderas sobre ellos $-\mathrm{y}$ no es poco que use el término mártir con naturalidad. Pero no explica en qué consiste ese martirio, aun cuando alude a él (nn. 98, 105, 140 y 275). El mártir es alguien bueno y admirable, ciertamente; imita lo bueno y admirable de Jesús. Pero parece como si "el martirio fuese un valor en sí, un ejemplo de vida heroica"22, no la consecuencia de una fidelidad específica en el seguimiento de Jesús: Jesús es dado muerte por anunciar e iniciar el reino a los pobres y por querer liberarlos del antirreino.

La cruz de Jesús no está en el centro de la cristología del documento, y ello no creo que se deba a una determinada limitación teológica conceptual, que se hubiera impuesto en la asamblea. Con clarividencia comenta José Comblin: "Da la impresión de que el texto quiso evitar cualquier referencia al conflicto con los romanos y con las autoridades de Israel. Es un evangelio sin conflicto, de pura bondad. ¿Por qué un evangelio sin conflicto? Para no tener que reconocer el sentido del martirio de tantos latinoamericanos crucificados en la segunda parte del siglo. Las elites quieren ocultar la responsabilidad histórica que tienen en esos martirios del siglo XX. El recuerdo de esos martirios ofende a las clases dirigentes de muchas naciones" ${ }^{23}$.

Volvamos a nuestra reflexión. Para saber qué hacer con los mártires, hemos dicho que tienen que estar bien ubicados, junto a Jesús de Nazaret. Por eso, a los mártires del tercer mundo nosotros los llamamos mártires jesuánicos. Son quienes "en vida y en muerte se parecen a Jesús" ${ }^{24}$. Casaldáliga lo recalca de mil maneras, e insiste - lo que es importante recordar ante el silencio de Aparecida- en que se parecen a Jesús en muerte. En su poema a Monseñor Romero afirma: "el Verbo se hizo muerte otra vez en tu muerte". Y lo historiza: "asesinado a sueldo, a dólar, a divisa. Como Jesús, por orden del Imperio". "Las curias no podían entenderte: ninguna sinagoga bien montada puede entender a Cristo".

Ya mencionamos, en una reflexión anterior, el respeto total y la admiración de don Pedro hacia todo aquel y aquella que da la vida, en definitiva, por Cristo-

22. J. Comblin, ibíd., p. 280.

23. Ibíd.

24. "Los mártires jesuánicos en el tercer mundo", Revista Latinoamericana 48 (1999) 237-255; "Nuestro mundo. Crueldad y compasión”, Concilium 299 (2003) 15-24. 
Jesús. Pero hay que recalcar que la cristología de don Pedro no es sólo una cristología de "virtudes", que hasta pudiera ser de inspiración burguesa, sino una cristología de "praxis", a favor de unos y en contra de sus opresores, lo cual hay que llevar a cabo "con" virtudes, pero "en medio" de la realidad tal cual es: opresora y conflictiva. Una cristología que lo ignore no expresa lo que sienten los pobres y de qué manera ellos entienden la vida y la muerte de Jesús. "Estamos en una situación de conflicto entre dos cristologías, una que es burguesa y otra que es la de los pobres. Este conflicto existe desde el inicio de la Iglesia" ${ }^{25}$.

Y sigue existiendo. Miles y miles son los mártires latinoamericanos, ellos y ellas, y que sepamos ninguno todavía ha sido reconocido oficialmente como tal. Aparecida habla bien de ellos, y es de agradecer, pero a ninguno de ellos se les ha concedido "el honor de los altares", palabras no muy evangélicas, por cierto. Y si están en camino, como Monseñor Romero, el proceso parece una carrera de obstáculos. Y ninguna de las explicaciones que se dan convence. Pienso que, en definitiva, existe un hondo no saber qué hacer con los mártires.

Monseñor Romero está vivo en los corazones de mucha gente - $\mathrm{y}$ en la fachada de la abadía de Westminster, en Londres, con otros diez mártires del siglo $\mathrm{XX}$ de las diversas iglesias cristianas. La Iglesia católica, sin embargo, sigue todavía pensando, al parecer, qué hacer con él. A Monseñor medio mundo le llama "mártir", y con toda naturalidad don Pedro Casaldáliga lo llamó "San Romero de América". En las curias, al menos en algunas y de las importantes, esto produce nerviosismo, y se exige una "reglamentación", que quiere decir "canonización", para podernos relacionar con Monseñor como cristiano ejemplar. Hasta don Pedro Casaldáliga tuvo que explicarse cuando leyó públicamente en la plaza de catedral de San Salvador su "San Romero de América". Y lo hizo con toda sencillez: "No estoy hablando desde cánones ni doctrina. Voy a leer una poesía".

Los pobres tienen muy desarrollado el sensus fidei y captan qué gente les habla del misterio de Dios. Y tienen también muy desarrollado el sensus amoris y captan qué gente les habla del amor de Dios. Si ellos usan el lenguaje de "mártir", "santo", algo importante quieren decir. Y en mi opinión, certeramente.

La polvareda que se levantó sobre si el martirio es por causa de la fe o por causa de la justicia debiera terminar. Un gran teórico, Karl Rahner, lo dijo muy bien: “¿Por qué no habría de ser mártir un Monseñor Romero, por ejemplo, caído en la lucha por la justicia en la sociedad, en una lucha que él hizo desde sus más profundas convicciones cristianas?" ${ }^{\text {. }}$. Y los pobres, los grandes de la vida real, ven que se parecen a Jesús. En ellos ven compasión hacia el débil, profecía contra el opresor, confianza y disponibilidad ante un Dios Padre, fortaleza y

25. Comblin, ibíd., p. 281.

26. "Dimensiones del martirio", Concilium 183 (1983) 323. 
entrega hasta la cruz. Y no es difícil entender este "parecido con Jesús" como "insigne testimonio de fe en Cristo".

\subsection{Ubicarlos bien entre nosotros como modelos e intercesores}

Los mártires son "intercesores" Les podemos pedir que nos den. Mucha gente lo hace, y algunos tienen fama de milagreros. Pero quizás pueden preguntarnos: “qqué más quieren que les demos?”. Hemos dado hasta la vida. Resuenan las palabras de Jesús: "les he dado ejemplo".

Los mártires son "modelos", y de ello estamos muy necesitados. Contentos debiéramos estar de que abundan entre nosotros. Son gente buena, ellos y ellas, que superaron el egoísmo y la corrupción, y nos ofrecen una desmesura de generosidad y de amor. Es difícil caminar como ellos. Pero con ellos, el caminar en la historia, con el pobre y hacia Dios, se hace más fácil.

¿Por qué preguntarnos qué hacer con los mártires? En definitiva, porque con ellos podemos ser humanos y cristianos. Así lo dice Pedro Casaldáliga:

Creemos que mientras haya martirio habrá credibilidad, mientras haya martirio habrá esperanza...

Mientras haya martirio habrá conversión, mientras haya martirio habrá eficacia...

Y con los mártires, la esperanza de liberación y resurrección.

En este mundo prostituido por el mercado total

y por el bienestar egoísta, os lo juramos con humildad y decisión:

" ¡Lejos de nosotros gloriarnos

a no ser en la cruz de nuestro Señor Jesucristo”

y en vuestras cruces hermanas de la suya!

Con Él y con vosotros y vosotras seguiremos cantando la Liberación.

Por Él y por vosotros y vosotras

sabremos jubilosamente

que nos toca resucitar "aunque nos cueste la vida" 27.

27. "Carta abierta a nuestros mártires”, Concilium 299 (2003) 171,173. 